\title{
Associative factors in the recall of connected discourse ${ }^{1,2}$
}

SHELDON ROSENBERG

Two passages, one of which contained words of high associative strength and the other words of low associative strength, were presented once by tape recorder and followed by a written recall test. On all measures of recall, performance in the high association group was superior to performance in the low association group. The results of a cloze test suggested that guessing may have contributed more to recall scores in the high association group than the low association group.

Since, when words are associatively related, recall tends to be facilitated in the case of lists of words (Deese, 1959) and lists of word sequences (Rosenberg, 1965), it is reasonable to expect that the presence of associative relationships between words will facilitate the recall of connected discourse (a series of interrelated sentences) as well. The present study was designed to evaluate this hypothesis in the case of the recall of content words in a short narrative. An attempt was made, also, to determine, through the use of a cloze procedure, the extent to which recall scores for such materials might be influenced by guessing from context, as has been suggested by Deese (1961). Subjects

Two classes of undergraduate students in educational psychology ( $\mathrm{N}=24$ and 30$)$ were divided in half at random and the halves in each class were randomly assigned to either the high associative strength (HA) discourse or the low associative strength (LA) discourse.

\section{Materials}

In preparing the $\mathrm{HA}$ discourse, stimulus and response words (mostly nouns and adjectives) were selected from the New Minnesota Norms (Palermo \& Jenkins, 1964) and made part of the content of the narrative. For each stimulus word, there were in the discourse from one to five responses of appreciable strength. In preparing the LA discourse, items that were designated as response words in the HA passage were replaced by items with the following characteristics: (1) very low (virtually zero) in associative relationship to the stimulus word; (2) comparable in T-L frequency; (3) appropriate semantically in the context of the discourse; (4) comparable grammatically. The two passages contained the same stimulus words and were identical in length. ${ }^{3}$ The passages were recorded on magnetic tape.

\section{Procedure}

The data for each condition were collected in two sessions in a group-testing situation. The $\mathrm{N}$ was 12 for the first session of each condition and 15 for the second. There was a one-trial presentation of each passage followed 4 sec. later by a 7-min. written recall test. The presentation time for each passage was approximately $63 \mathrm{sec}$. The Ss in each group were told to try to remember as much of the passage as they could, and, for the recall test, to write down as much of the passage as they could recall and to try to guess at items they were not sure of.

\section{Resulis and Discussion}

Since the differences between LA and HA were comparable for both sessions, the data from the two sessions were combined. In scoring recall, the location of an item was not considered. There were 16 possible stimulus words and 16 possible $\mathrm{R}-1$ words. In the HA discourse, the R-1 word for each stimulus word was the strongest response word according to the norms, and in the LA discourse, it was the low-strength counterpart. Since some stimulus words had more than one response, another measure of recall, R-2, was computed based upon the total number of response words recalled.

The mean number of stimulus words and $R-1$ words recalled in Group HA were, respectively, $9.26(\mathrm{SD}=3.17$ ) and $8.07(\mathrm{SD}=2.96)$, and in Group LA, $7.22(\mathrm{SD}=2.58)$ and $4.78(\mathrm{SD}=2.78)$. An analysis of variance revealed an $\mathrm{F}=14.10, \mathrm{df}=1 / 52, \mathrm{p}<.001$, for associative strength and an $F=33.33$, df $=1 / 52, p<.001$, for stimulus words vs. R-1 words. The interaction was nonsignificant. In general, it can be seen that recall of stimulus words and R-1 words from the HA discourse was significantly higher than recall of stimulus words and R-1 words from the LA discourse. In addition, for both passages, significantly more stimulus words were recalled than R-1 words. Possibly, there were greater contextual constraints for the stimulus words in the passages than for the R-1 words.

The mean number of $\mathrm{R-2}$ words recalled in Group $\mathrm{HA}$ was $13.00(\mathrm{SD}=3.98)$ and in Group LA, $7.85(\mathrm{SD}=4.30)$. The t-test comparison of these means resulted in a $t=4.56(\mathrm{df}=52)$, which was significant beyond the .001 level (one-tailed). A t-test was also made for the comparison of the mean number of stimulus and $\mathrm{R}-1$ word pairs recalled. Group HA recalled on the average $6.15(\mathrm{SD}=3.01)$ such pairs, and Group LA, 3.04 $(\mathrm{SD}=2.62)$. The value of $t=4.09 \quad(d f=52)$ was also significant beyond the .001 level (one-tailed).

The recall dependencies between stimulus and $\mathrm{R}-1$ words, and between R-1 and stimulus words were also analyzed. The question that was asked, in the case of, for example, the stimulus word, $R-1$ word contingencies 
was what proportion of the stimulus words recalled were accompanied by their appropriate $\mathrm{R}-1$ words on the recall sheet. The mean S-R dependencies in Groups $\mathrm{HA}$ and LA, respectively, were $.64(\mathrm{SD}=.22)$ and .40 $(\mathrm{SD}=.24)$, and $\mathrm{R}-\mathrm{S}$ dependencies, $.72(\mathrm{SD}=.25)$ and $.56(\mathrm{SD}=.24)$. The stronger dependencies in the $\mathrm{R}-\mathrm{S}$ direction were most likely the result of the higher level of recall of stimulus words. An analysis of variance of these data revealed an $F=9.40, d f=1 / 52, p<.01$, for associative strength and 25.75, $\mathrm{df}=1 / 52, \mathrm{p}<.001$, for directionality. The interaction was nonsignificant.

These results suggest strongly that associative habit plays an important role in the recall of connected discourse. In trying to account for the observed facilitation, one possibility considered was guessing habits. If, during written recall, an individual tries to guess at words, his guessing behavior is likely to be influenced by the items he has already recalled. Associative theory would predict that what he does guess will frequently be a high strength associate of a recalled item. Now, if that high strength associate is part of the original material he is trying to recall, his recall score will be enhanced.

In an attempt to evaluate this possibility, the $\mathrm{HA}$ and LA passages were printed on sheets of paper and presented to Ss who had not participated in the learning study. There were four groups of $15 \mathrm{Ss}$ each, and the groups were differentiated in terms of whether they received the $\mathrm{HA}$ or the $\mathrm{LA}$ discourse and whether the stimulus words or the R-1 words were deleted. The $S^{\prime}$ 's task was simply to guess at the missing items. The data were collected in a group-testing situation and all Ss were permitted to complete the task.

The Ss given the HA discourse guessed correctly on the average 8.47 (out of 16) of the stimulus words and 7.87 of the R-1 words, while the Ss given the LA discourse had a mean of 4.00 for the stimulus words and .20 for the R-1 words. Guessing scores were clearly higher in the case of words deleted from the HA discourse. Since the LA discourse contained the same stimulus words as the HA discourse, the wrong guesses by $\mathrm{Ss}$ in Group LA were examined to determine whether any high strength associates had occurred. The mean number of R-1 words from the HA discourse guessed by Ss in Group LA was 7.93 .

This last finding suggested that $\mathrm{Ss}$ in the recall study in Group LA should have also produced some high associative strength words. In scoring the recall protocols for this factor, it was discovered that LA Ss had produced during recall a mean of 3.30 high strength responses.

In view of these findings, it is possible that performance in the recall study may have been more a function of guessing in the case of the HA discourse than the LA discourse. This is not to say, however, that other factors were not involved. It is possible, for example, that during presentation of a passage, when a stimulus word occurs, it tends to elicit, implicitly, some of its associates, and in the case of the presence of bidirectional strength, if the associates occur in the same passage, they may tend to elicit, implicitly, the stimulus word. What this would mean, essentially, is that the frequency of occurrence (overt + implicit) of associatively related words would be greater than would be the case for words of low associative strength, with the possible result that recall of an HA discourse would be facilitated. Some evidence for the possible operation of implicit associative responses in verbal behavior has been presented recently by Underwood (1965).

\section{References}

Deese, J. From the isolated verbal unit to connected discourse. In C. N. Cofer and Barbara S. Musgrave (Eds.), Verbal learning and verbal behavior. New York: McGraw-Hill, 1961.

Deese, $\mathbf{J}$. Influence of inter-item associative strength upon immediate free recall. Psychol. Rep., 1959, 5, 305-312.

Palermo, D. S., \& Jenkins, J. J. Word association norms: Grade school through college. Minneapolis, Minnesota: University of Minnesota Press, 1964.

Rosenberg, $\mathbf{S}$. The influence of grammatical and associative habits on verbal learning. In $\mathrm{S}$. Rosenberg (Ed.), Directions in psycholinguistics. New York: Macmillan, 1965.

Underwood, B. J. False recognition produced by implicit verbal responses. J. exp. Psychol., 1965, 70, 122-129.

\section{Notes}

1. This study was supported by grant $\mathrm{MH}$ 08904-02 from the National Institute of Mental Health, U. S. Public Health Service. 2. Based upon a paper presented at the Psychonomic Society meeting, Chicago, October, 1965.

3. HA discourse-The tall man sat on a chair in front of a low table, while the pretty woman played soft music on the piano. The table was piled high with food. There was cheese and crackers, bread and butter and some cold fruit and a hot vegetable as well. A young girl sat on the floor on the yellow carpet reading a book, while a small boy played with some toys on a blue rug in the middle of the room. The man was a soldier in the army and had just returned from the war that day. Although there had been much to eat on the train, the sight of all that food made him hungry again. The atmosphere was one of joy. They were all happy to be together again. Outside the moon and stars shone brightly in the June sky, and the green grass sparkled in the night.

4. LA discourse-The dark man sat on a pillow in front of a small table, while the gentle lady played good music on the organ. The table was piled high with things. There was cheese and salad bread and juice and some cold fruit and a dry meat as well. A fine girl sat on the blanket on the yellow carpet reading a book, while a small dog played with some toys on a purple cloth in the middle of the room. The man was a soldier in the draft and had just returned from the field that day. Although there had been much to taste on the train, the sight of all that dinner made him hungry again. The atmosphere was one of joy. They were all relieved to be together again. Outside the moon and lake appeared clearly in the June evening, and the green house sparkled in the valley. 